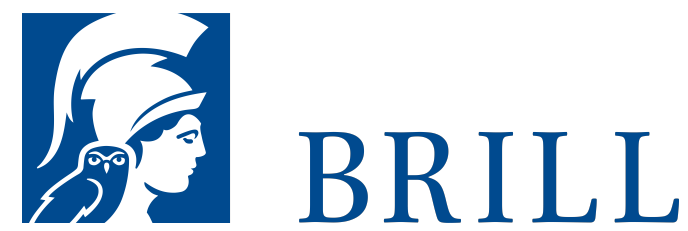

\section{"Ich bin Realist, wie es noch kein Mensch vor mir gewesen ist"}

Friedrich Heinrich Jacobi über Idealismus und Realismus

Authors: Birgit Sandkaulen and Birgit Sandkaulen

For ages, the significance of the Düsseldorf philosopher and novelist Friedrich Heinrich Jacobi (1743-1819) has been fully ignored. Heinrich Heine spread the rumor that Jacobi was an irrational fideist, responsible for no important philosophical contribution. This mistaken assessment now belongs to the past. It is clear from his writings and correspondence that Jacobi was along with Kant largely responsible for sparking key intellectual debates of the beginning of the modern era. The provocative power with which he advanced these debates anticipated even contemporary discussions. One good example of this is the debate about idealism versus realism.

Über lange Zeit war die Bedeutung des Düsseldorfer Philosophen und Romanautors Friedrich Heinrich Jacobi (17431819) völlig überdeckt. Heinrich Heine beförderte das Gerücht, daß Jacobi ein irrationaler Fideist gewesen sei, dem wir keinerlei wichtigen Impuls verdanken. Inzwischen gehört diese Fehleinschätzung der Vergangenheit an. Jacobi hat in seinen Schriften und in seiner Korrespondenz nicht nur neben Kant die maßgeblichen Anstöße für die intellektuellen Debatten der beginnenden jüngeren Moderne gegeben. Die provokative Kraft, mit der er diese Debatten vorangetrieben hat, weist darüber hinaus auch in gegenwärtige Diskussionen voraus. Die Debatte über Idealismus und Realismus zeigt das exemplarisch.

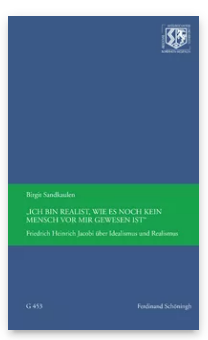

Pages: 38 Seiten, $1 \mathrm{~s} / \mathrm{w}$ Abb.

Language:

German

Subjects:

General,

Philosophy

Publisher: Brill |

Schöningh

Series:

Nordrhein-

Westfälische

Akademie der

Wissenschaften und

der Künste - Vorträge:

Geisteswissenschaften,

Volume: 453

E-Book (PDF)

Released online:

28 Apr 2020

ISBN: $978-3^{-}$

657-78837-8

List price

Paperback

Publication date:

11 Aug 2017

ISBN: 978-3-

506-78837-5

List price 
Biographical Note

Birgit Sandkaulen ist Professorin für Klassische Deutsche Philosophie an der Ruhr-Universität Bochum.

For more information see brill.com

\begin{abstract}
Order information: Order online at brill.com +44330 333 0049 | customerservices@brill.com Submission information: brill.com/authors
\end{abstract}

Titles published by Brill | Fink, Brill | mentis or Brill | Schöningh: +49(o)71 5413279216 | brill@brocom.de 